\title{
Age and growth of round gobies in Lake Huron: implications for food web dynamics
}

You J. Duan ${ }^{\mathrm{a}}$, Charles P. Madenjian ${ }^{\mathrm{b}}$, Cong X. Xie ${ }^{\mathrm{a}}$, James S. Diana ${ }^{\mathrm{c}}$, Timothy P. O’Brien ${ }^{\mathrm{b}}$, Ying M. Zhao ${ }^{\mathrm{e}}$, Ji X. He ${ }^{\mathrm{d}}$, Steven A. Farha ${ }^{\mathrm{f}}$, Bin Huo ${ }^{\mathrm{a} *}$

${ }^{\mathrm{a}}$ Huazhong AgriculturalUniversity, College of Fisheries, Wuhan, Hubei 430070, China

${ }^{\mathrm{b}}$ U.S. Geological Survey, Great Lakes Science Center, 1451 Green Road, Ann Arbor, MI 48105, USA

${ }^{\mathrm{c} S}$ School of Natural Resources and Environment, University of Michigan, Ann Arbor, MI48109, USA

${ }^{\mathrm{d}}$ Michigan Department of Natural Resources, Lake Huron Research Station, 160 East Fletcher Street, Alpena, MI 49707, USA

${ }^{\mathrm{e}}$ Ontario Ministry of Natural Resources, Aquatic Research and Development Section, 320 Milo Road, Wheatley, ON NOP 2PO, Canada

${ }^{\mathrm{f}}$ U.S. Geological Survey, Great Lakes Science Center, Hammond Bay Biological Station, 11188Ray Road, Millersburg, MI 49759, USA

*Corresponding author:E-mail address: huobin@mail.hzau.edu.cn

Tel: +86 13476008200. Fax: +86 2787282114 
Abstract:Although the round goby (Neogobius melanostomus)has become established throughout the Laurentian Great Lakes, information is scarce on spatial variation in round goby growth between and within lakes. Based on a sample of 754 specimens captured in 2014, age, growth, and mortality of round gobies at four locations in Lake Huron were assessed via otolith analysis. Total length (TL) of round gobies ranged from 44 to111 mm for Saginaw Bay, from 45 to 115 mm for Rockport, from 50 to 123 mm for Hammond Bay, and from 51 to118 mm for Thunder Bay.Estimated ages of round gobies ranged from 2 to 5 years for Saginaw Bay, from 2 to 6 years for Rockport, and from 2 to 7 years for Hammond Bay and Thunder Bay. Sex-specific, body-otolith relationships were used to back-calculatetotal lengths at age, which were then fitted to von Bertalanffy growth models. For each sex, round goby growth showed significant spatial variation among the four locations within Lake Huron.At all fourlocations inLake Huron, males grew significantly faster than femalesand attaineda larger asymptotic length than females. Annualmortality rate estimates were high (62 to 85\%), based on catch-curve analysis,suggesting that round gobies may be under predatory control inLake Huron.

Index words: Age structure; Mortality; Round goby; Spatial variation in growth; Top-down control 


\section{Introduction}

Not only do species invasionsmotivate extensive concern over their effects on native species and ecosystem function, butinvasive species can become important components of the Laurentian Great Lakes food webs (Charlebois et al., 2001). Invasive species can influence food web dynamics by competing with native fauna for space or by interfering with natural reproduction of native species (Charlebois etal., 1997; MacInnis and Corkum, 2000a; Ruiz et al., 1997). Although negative effects of aquatic invaders are often highlighted in the scientific literature (Charlebois etal., 1997; MacInnis and Corkum, 2000a; Rodriguez, 2006), aquatic invaders may also become an important food resource for native fauna (Crane et al., 2015). Once a new species becomes established, it is essential to attempt to understand its complex role within the ecosystem aschanges in the abundance of the new species can have a variety of ecosystem effects (Zavaleta et al., 2001). Additionally, research on established populations of non-native species can answer fundamental questions in ecology and guide future control methods and effective maintenance management (Simberloff, 2003).

The first record of the round goby (Neogobius melanostomus)invasion of the Laurentian Great Lakes basin was the capture of round gobies in the St. Clair River in 1990 (Jude et al., 1992). Since that time, the invasive round goby has become well established in four of five Laurentian Great Lakesand has become a significant component oftheirfood webs (He et al., 2015; Johnson et al., 2005; Kornis et al., 2012).Predicted ecological effectsinduced by the round goby invasion include theexclusion of native benthic fish species due to competition for spawning space, 
habitat and dietaryresources (French and Jude, 2001; Janssen and Jude, 2001; Jude et al., 1995; Jude, 1997), predation on eggs and fry of native fishes (Chotkowski and Marsden, 1999; Phillips et al., 2003; Steinhart et al., 2004), support of piscivore biomass by providing an alternative energy source (Dietrich et al., 2006;He et al., 2015; Madenjian et al., 2011; Pothovenand Madenjian, 2013;Truemper and Lauer, 2005), and serving as a conduit to funnel dreissenid energy production to upper trophic levels of the food web(Johnson et al., 2005).Nevertheless, much more research is needed to fully determine the extent of these and other predictedecological impacts of round gobies on food webs of the invaded aquaticecosystems.

Knowledge oflife-history variables, such as age composition, growth and mortality rate,is essential for predicting long-term effects of nonindigenous species on food webs and for establishing practical management policies to control non-native species (Veitch and Clout, 2002). Previous studies on round goby age and growth within invaded ecosystems indicated that size within an agegroup was highly variable and males grew faster and attained a larger maximum size than females (French and Black,2009; Gümüs and Kurt, 2009; MacInnis and Corkum, 2000a,2000b;Phillips et al., 2003; Sokołowska and Fey, 2011; Taraborelli et al.,2010). Moreover, life-history characteristics were found to vary over time and space. With regard to time, Grul'a et al. (2012) reported that round gobies in the middle Danube Riverallocatedenergy resources to reproduction and offspringcarein newly established populations, which were characterized by negative allometricgrowth. However, in longer established populations there was positive allometric growth which resulted in a shift in allocation 
towards somatic growth. Lynch and Mensinger (2013) determined that round gobies in Duluth Harbor of Lake Superior demonstratedmaximum growth in July and August and almost no growth between October and March.With regard to space, Huo et al. (2014) reported that round gobygrowth showed significant spatial variation withinLake Michigan. Round gobiesat Sleeping Bear Dunes and Waukegan grew significantly faster than those at Sturgeon Bay.

Available information on round goby mortality rates in the Laurentian Great Lakesis limited. Round gobies experienced an annual mortality of 0.33 in the Duluth Harbor, while estimated annual mortalities ranged from 0.26 to 0.44 in Hamilton Harbour of Lake Ontario (Lynch and Mensinger, 2013; Vélez-Espino et al., 2010). Bunnell et al. (2005) reported that the annual mortality rate of round gobies in open waters of the central basin of Lake Erie was 0.62, while Huo et al. (2014) showed that estimated annual mortality rates of round gobies in three locations of Lake Michiganvaried from 0.79 to 0.84 .To date,growth rates and mortality rates for round gobies in Lake Huron have not been investigated.

The primary goal of our study was to determine whether round goby growth showed significant spatial variation among four different locations of Lake Huron. The secondary goal of our study was to estimate roundgoby mortality rates for Lake Huron. Our specific objectives were to:(1) age round gobies from four different locations of Lake Huron usingotoliths, (2) establish a back-calculation formula and then back-calculate total lengths at age for use in growth analyses, (3) compare growth among the fourlocations, (4) compare growth between the sexes, and (5) 
estimatemortality rates at the fourlocations using catch-curve analysis.

\section{Materials and methods}

We primarily relied on routine annual sampling to obtain round gobies from Saginaw Bay, Thunder Bay, and Rockport in Lake Huron during 2014, but we also conducted some supplementary sampling at Hammond Bay to obtain additional round gobies (Fig. 1). The Michigan Department of Natural Resources conducts a bottom trawl survey of Saginaw Bay and Thunder Bay each year, whereas the U. S. Fish and Wildlife captures round gobies from Rockport each year using minnow traps.Round gobieswere captured using minnow trapsdeployed at depths ranging from 3 to $20 \mathrm{~m}$ atRockport and Hammond Bay duringAugust and September 2014, while round gobieswere caught using bottom trawlstowed at depthsranging from 20 to $27 \mathrm{~m}$ inThunder Bay during July and August 2014and at depths between 11 and 12 m inSaginaw Bay during September 2014. All bottom trawling was conducted over soft bottom areas of the lake. At Rockport, minnow traps were placed over silty or sandy areas adjacent to large boulders used to construct the pier. In Hammond Bay, the bottom substrate consisted of a mix of silt, sand, rock cobble, and a few large rocks. All fish were immediately frozen and transported back to the laboratory. After specimens were thawed, total length (TL) was measured to the nearest $1 \mathrm{~mm}$. All individuals were sexed based on shape of the urogenital papilla (Kornis et al., 2012).

Both sagittal otoliths were extracted from each fish, washed withethanol, air-dried, and then stored in labeled test tubes. Typically, left otoliths were prepared for age estimationby cutting, grinding, and polishing according to the method ofHuo 
et al. (2014).Age was estimated by counting annuli on the otolith using a microscope at $\times 100$ magnifications under transmitted light. Three readerswith no prior knowledge of the length, sex, or time of capture of the fish participated in age estimation.All ages were determined by two of the three readers. If both readings were inagreement, the agreed-upon age was assigned to the round goby. Ifthe two readings differed, then the otolith was read by the third reader. If thethird reading did not agree with either of the other readings, then noage assignment was made for that fish. If the third reading agreedwith one of the previous two readings, the age for which there wasagreement was assigned to that fish.

A digital picture of each otolith was taken using an Olympus BX51 photo-microscope, and then otolith radius $(O R)$ was measured as described by Huo et al. (2014). Measurements to thenearest $0.001 \mathrm{~mm}$ were carried out using Image Pro Plus V6.0 software on a personal computer. The relationship between $\log _{10}$-transformed total length $(T L)$ and $\log _{10}$-transformed otolith radius was characterized using simple linear regression, and we refer to thisrelationship as the body-otolith relationship in discussions below.

We used back-calculation based on the body proportional hypothesis (Francis, 1990) to reconstruct the growth historyof each round goby. The ratio of the otolith radius at one age to the otolith radius at another age is a function of thefish length at these two ages, andthis function could be linear or nonlinear(Francis, 1990). Preliminary analysis of total length-otolith radiusdata revealed that logarithm of total length was linearly related to logarithm of otolith radius. Thus, we 
back-calculatedround goby totallength using the following relationship:

$\log _{10}\left(T L_{\mathrm{n}}\right)=\log _{10}(T L)+a \times\left(\log _{10}\left(O R_{\mathrm{n}}\right)-\log _{10}(O R)\right)$

where $T L_{n}$, total length at annulus $n ; T L$, observed total length; $O R_{n}$, otolith radius at annulus n; OR, otolith radius; $a$, the slope of the linear function between logarithm of total length and logarithm of otolith radius. To avoid the potential for autocorrelated growth increments of an individual fish, we only back-calculated total lengths at the ages corresponding to the two most recent annuli on the otolith for each fish. In addition, Francis (1990) recommended that total lengths be back-calculated under both the body proportional and structure size proportional hypotheses, and results be compared to check on the robustness of the back-calculation procedure. Following the advice of Francis (1990), we back-calculated total lengths for the round gobies under both hypotheses, although we present only the results from the body proportional hypothesis in this paper. Growth curves and inferences regarding differences in growth between sexes and locations were similar for both hypotheses, indicating that our conclusions were robust to the back-calculation procedure. Our back-calculation procedure was based on the implicit assumption that the proportional relationship between total length and otolith radius was consistent throughout the fish's lifetime, including its embryonic development phase. Thus, the biological intercept, as defined by Campana (1990), was assumed to occur at total length equal to zero and otolith length equal to zero. Measurements of total lengths and otolith lengths by Azour et al. (2015) of round gobies from the Baltic Sea, over a wide range of round goby sizes, suggested that this assumption was valid. 
For each combination of location and sex, simple linear regression was used to estimatethe slope of the body-otolith relationship. Inaddition, we used analysis of covariance (ANCOVA) to determine ifslopes of the body-otolith relationship differed between sexes ateach of the fourlocations. For each sex, we also used ANCOVA to determine if slopes of the body-otolith relationship differed among the four locations.For each ANCOVA model, $\log _{10}(T L)$ was the dependent variable, sex or location was the treatment effect, $\log _{10}(O R)$ was the covariate, and the interaction between the treatment effect and the covariate was also included in the model. The $F$ test for significance of the interaction term was equivalent to the $F$ test for equality of slopes. Analyseswere carried out using SPSS 16.0 (Chicago, IL) and Lab Origin pro 8.0 (Originlab, Northampton, MA). We set $\alpha=0.05$ for all of our statistical testing. If, for a given sex, the above-mentioned testing for equality of slopes indicated that the slopes did not significantly differ among the four locations, the interaction term was eliminated from the ANCOVA model. We then used the $F$ test for significance of the location effect as a test for equality of the intercepts among the four locations. If intercepts significantly varied among the four locations, the ANCOVA model with location as the treatment effect and $\log _{10}(O R)$ as the covariate was used to estimate the value of the slope, $a$, and this value was used to back-calculate total lengths for round gobies from all four locations. On the other hand, if testing for equality of intercepts revealed that the intercepts did not significantly vary among the four locations, data from all four locations were pooled, and simple linear regression analysis was applied to $\log _{10}(T L)$ as a function of 
$\log _{10}(O R)$. The estimate of the slope, $a$, was then used to back-calculate total lengths for round gobies from all four locations. If the above-mentioned testing for equality of slopes indicated that the slopes did significantly vary among the four locations, we applied simple linear regression analysis to $\log _{10}(T L)$ as a function of $\log _{10}(O R)$, by location, to estimate $a$ for each location. Then, the estimate of $a$ was used to back-calculate total lengths.

For each combination of location and sex, a von Bertalanffygrowth model was fitted to total lengths calculated from the above equation. AGauss-Newton nonlinear regression algorithm was used to estimateparameters in the von Bertalanffy growth model. The likelihood ratio test, as described by Quinn and Deriso (1999), was used todetermine whether fitted von Bertalanffy growth models differedsignificantly between sexes for each of the fourlocations. In addition, for each sex, we tested for pairwise differences in fitted vonBertalanffy growth models among the four locations of Lake Huron using likelihood ratio tests, and a Bonferroni correction was applied to these six pairwise comparisons amonglocations.

Catch-curve analysis was used to estimate round goby mortalityrates at the fourlocations of Lake Huron (Ricker, 1975). We first determined age at which round gobies were fully recruited to the sampling gear by examining the catch curves for each location (Quinnand Deriso, 1999; Ricker, 1975), and then we used the right truncation method to exclude old age groups, with catches less than 5 from the data sets of each locationdue to the extreme variation that could be introduced by the collection of, or failure to collect, a few individuals (Smith et al., 2012; Van Den 
Avyle and Hayward, 1999). Simple catch curves were used for the four locations because round gobies weresampled for just 1 year (2014) in all fourlocations (Ricker, 1975). If sufficient data were available, simple linear regression wasused to fit a regression line to $\log _{\mathrm{e}}$-transformed catch-at-ageas a function of age. Simple linear regression yielded an estimate of instantaneous mortality rate $Z$, and annual survival $S$ is equal to $\mathrm{e}^{-Z}$. However, if only two data points were available on the descending limb of the catch curve, we simply calculated the ratio of catch at the older ageto peak catch to estimate annual survival. Annual mortality is equal to $1-S$. Variance of the annual survivalestimate was calculated by the delta method (Seber, 1982). For a particularlocation, variance $\left(\sigma^{2}\right)$ and standard error (SE) for the annual survival estimatewere equal to $\sigma^{2}$ and SE, respectively, for the annual mortalityestimate. When only two data points were available on the descending limb of the catch curve, variances of survival and mortality estimates could not be estimated. Due to low sample sizes of the older ages, especially for the females, we pooled catches of males and females to estimate mortality rates for both sexes pooled.Similarly, Huo et al. (2014) pooled catches of males and females to estimate mortality rates of Lake Michigan round gobies for both sexes pooled.

\section{Results}

\section{Length composition}

The size distribution of round gobieswas unimodal atall four locations of Lake Huron (Fig. 2). For males, total lengths of Saginaw Bay round gobies varied from 44 to $111 \mathrm{~mm}$, withmodal size from 50 to $65 \mathrm{~mm}$;total lengths of Rockport round gobies 
varied from 46 to $113 \mathrm{~mm}$, with the most dominant classes from 65 to $85 \mathrm{~mm}$; total lengths of Hammond Bay round gobies varied from52 to $123 \mathrm{~mm}$, with the most frequent classes from 65 to 85 mm; total lengths of Thunder Bay round gobies ranged from51 to $118 \mathrm{~mm}$, with the most frequent classes from 65 to $80 \mathrm{~mm}$ (Fig. 2).

For females, total lengths of Saginaw Bay round gobies varied from51 to $90 \mathrm{~mm}$, with the modal size from 60 to 70 mm;total lengths of Rockport round gobies varied from45 to $115 \mathrm{~mm}$, with the most dominant classes from 55 to $65 \mathrm{~mm}$; total lengths of Hammond Bay round gobies varied from50 to $87 \mathrm{~mm}$, with the most frequent classes from 55 to 70 mm;total lengths of Thunder Bay round gobies ranged from52 to 106 mm, with the most frequent classes from65 to $80 \mathrm{~mm}$ (Fig. 2 ).

Age composition

We were able to assign an age to all but 4 of 754 otoliths by agreement from multiple readings. For males, age estimatesranged from 2 to 7 yearsfor Hammond Bay and Thunder Bay, from 2 to 5 yearsfor Saginaw Bay,and from 2 to 6 years for Rockport (Fig. 3). For females, age estimates ranged from 2 to 4 years for Saginaw Bay, from 2 to 6 years for Rockport, from 2 to 5 years for Hammond Bay, and from 2 to 7 years for Thunder Bay (Fig. 3). Thus, both sexes of round gobies attained an age of 7 years in Lake Huron.

\section{Body-otolith relationship}

For both sexes, slopes of the body-otolith relationshipsdid not significantly differ among four locations of Lake Huron (Fig. 4; Table 1). However, slope for maleswas significant greater than slopefor females at Saginaw Bay, whereas slopes did not 
significantly differ between sexes at Rockport, Hammond Bay,or Thunder Bay (Table 2). Because the slopes did not significantly differ among four locations of Lake Huron, the slope terms were dropped from the ANCOVA model to test on the equality of intercepts among four locations.For both sexes, intercepts varied significantly among the four locations (ANCOVA, all $P<0.001$ ). Thus, an ANCOVA model with location as the treatment effect and $\log _{10}(O R)$ as the covariate was used to estimate the value of the slope, $a$, for each sex.

For females:

Saginaw Bay: $\log _{10}(T L)=0.807 \times \log _{10}(O R)+1.911\left(\mathrm{~N}=100, R^{2}=0.497\right)$

Rockport: $\log _{10}(T L)=0.807 \times \log _{10}(O R)+1.894\left(\mathrm{~N}=37, R^{2}=0.808\right)$

Hammond Bay: $\log _{10}(T L)=0.807 \times \log _{10}(O R)+1.906\left(\mathrm{~N}=74, R^{2}=0.688\right)$

Thunder Bay: $\log _{10}(T L)=0.807 \times \log _{10}(O R)+1.941\left(\mathrm{~N}=100, R^{2}=0.583\right)$

For males:

Saginaw Bay: $\log _{10}(T L)=0.966 \times \log _{10}(O R)+1.945\left(\mathrm{~N}=101, R^{2}=0.722\right)$

Rockport: $\log _{10}(T L)=0.966 \times \log _{10}(O R)+1.947\left(\mathrm{~N}=115, R^{2}=0.690\right)$

Hammond Bay: $\log _{10}(T L)=0.966 \times \log _{10}(O R)+1.973\left(\mathrm{~N}=126, R^{2}=0.601\right)$

Thunder Bay: $\log _{10}(T L)=0.966 \times \log _{10}(O R)+1.980\left(\mathrm{~N}=97, R^{2}=0.681\right)$

\section{Growth}

For both sexes, round gobygrowth showed significant spatial variation within Lake Huron (Fig. 5; Table3). Round gobies at Thunder Bay grew significantly faster than round gobies at Hammond Bay, Rockport, and Saginaw Bay(Fig. 5).Males grew significantly faster than females (Table4), and attained larger asymptotic length than 
females at all four locations of Lake Huron (Table 5).Round gobies can reach 7 years of age for both sexes in Lake Huron, where some of the oldest round gobies noted in the literature have been found (Table 6).

\section{Mortality}

Round gobies werefully recruited to the gear by age 3atSaginaw Bay, while theydid not fully recruit until age 4 at Rockport, Hammond Bay, and Thunder Bay. Instantaneous mortality rate, estimated by catch-curve analysis, was 1.085/year (SE=0.226/year) for the round goby population atHammond Bay(Fig. 6), giving an annual mortality rate of $66 \%$. Annual mortality ratesat Rockport, Thunder Bay,and Saginaw Bay were estimated to be68\%,62\%, and 85\%,respectively.Variances could not be estimated for Saginaw Bay, Rockport, and Thunder Bay because only two points were available on the descending limb of the catch curve.

\section{Discussion}

Round gobies at Thunder Bay grew significantly faster than round gobies at Hammond Bay, Rockport and Saginaw Bay. This spatial variation may be due to spatial differences in the quality and quantity of food, as well as spatial differences in other environmental factors. Similarly, Huo et al. (2014) and French and Black (2009) explained spatial variation in round goby growth in Lake Michigan and Lake Huron by invoking spatial variation in food quality and quantity and in other environmental factors. In a feeding experimentconducted by Coulter et al. (2011), round gobies feddreissenid mussels had significantly lower growth than individuals fed juvenile fish and chironomids and displayed the same weight loss as round gobies fed only 
zooplankton. Thus, round goby growth likely depends on the availability of zooplankton, dreissenid mussels, juvenile fish, and chironomids, as well as the pursuit times and search costs for each of these diet items. Environmental factors, such as water temperature, photoperiod, and water depth experienced byround gobies may have also contributed to observed growth differences amonglocations. In addition, round goby population density may have affected round goby growth.

Predation is likely an important factor controlling round goby survival in Lake Huron.Over the past 20 years, the invasive round goby has become established in the Laurentian Great Lakes (Kornis et al., 2012) and has been incorporated into the diet of a broad array of piscivorous fishes (Dietrich et al., 2006; Madenjian et al., 2011; Pothoven and Madenjian, 2013; Truemper and Lauer, 2005). Coupling our findings with those of He et al. (2015), round gobiesin Lake Huronappear to be under predatory control by piscivores, including lake trout (Salvelinus namaycush), walleye (Sander vitreus), and lake whitefish (Coregonus clupeaformis).We estimated that round goby annual mortality was relatively high (> 60\%) at all four locations in Lake Huron. He et al. (2015) reported annual consumption estimates of round gobies by piscivore populations that were as high as, or exceeded, annual consumption estimates of either alewives (Alosa pseudoharengus) or rainbow smelt (Osmerus mordax) during 2003-2010, and abundances of bothwere thought to be strongly influenced by piscivore populations in Lake Huron. Results from our study indicated that round gobies in Saginaw Bay experienced higher mortality than those in other locations in Lake Huron, as annual mortality rate in Saginaw Bay was estimated to be $85 \%$. 
Undoubtedly, predation by walleyes contributed to this relatively high mortality rate, as round gobies predominate the present-day diet of walleyes caught in Saginaw Bay (Jovanovic, 2013). In addition, freshwater drum (Aplodinotus grunniens), channel catfish (Ictalurus punctatus), and yellow perch (Perca flavescens)feed on round gobies in Saginaw Bay (Fielder and Thomas, 2006; Fielder et al., 2007).Annual mortality rates were also relatively high at Hammond Bay, Rockport and Thunder Bay, where predation by lake whitefish, lake trout, and walleye may be important (He et al. 2015; Pothovenand Madenjian 2013).

This study demonstrated for the first time that life span of the round goby can reach 7 years for both sexes in Lake Huron,and that thesefish are among the oldest round gobies noted in the literature. Age estimation for round gobies appears to depend on aging technique. A great deal of research has documented that sectioned otoliths provide the most precise and accurate age estimates (Gunn et al., 2008; Phelps et al., 2007), partly because otoliths are metabolically inert and not subject to resorption and partly because thin sectioning affords better resolution of the annuli (Phelps et al., 2007; Sponaugle, 2009). In addition, observed round goby growth in Lake Huron was slow compared withliterature from theirnative range in the Ponto-Caspian region(Nikolske, 1956; Gümüs and Kurt, 2009).Perhaps this relatively slow growth also contributes to the apparent greater longevity in Lake Huron than in the native range.

Although two different gears were deployed to catch the round gobies used inour study, andeach gear has its own sampling bias, ranges in totallengths of roundgobies 
used for aging were very similar between different gears. Further, theround goby length-frequency distributions were also similar. Thus, samplingbias with regard to round goby size did not appear to drastically differ between gears. Nonetheless, the sampling bias for either gear has not been quantified.

Not only does our study represent an important step in the understanding of round gobybiological characteristics, but results providefurther evidence for predatory control of round gobies in Lake Huron, given relatively high mortality rates in three of four locations. Thus, our study findings supported those of He et al. (2015), who proposed that piscivores were exerting top-down control on round goby abundance in Lake Huron based on relatively high estimates of annual consumption of round gobies by piscivore populations. Likewise, round goby populationsappeared to be under predatory control in Lake Michigan (Huo et al., 2014) as well as in eastern Lake Erie (Madenjian et al., 2011). Further assessment of the trophic linkages between predators and round gobiesin the Great Lakes is needed to completely understand the role of round gobies in the Laurentian Great Lakes.

\section{Acknowledgments}

We thank Andrew Briggs of the U. S. Fish and Wildlife Service Detroit River International Wildlife Refuge for providing round gobies from Rockport, Todd Wills and Mike Thomas of the Michigan Department of Natural Resources Lake St. Clair Fisheries Research Station for providing round gobies from Saginaw Bay, Henry Thompson and Zach Wickert of the USGSHammond Bay Biological Station for collection of round gobies in Hammond Bay;Patrick Hudson and Kevin Keeler for 
assisting with the use of the microscope-camera system,David Bennion for preparing the mapandDavid Jude for reviewing the draft manuscript and providing helpful suggestions for its improvement. This study was funded,in part, by the Chinese Scholarship Council. Use of trade, product, orfirm names does not imply endorsement by the U. S. Government.This article is Contribution 0000 of the U. S. Geological Survey GreatLakes Science Center.

\section{References}

Azour, F., van Deurs, M., Behrens, J., Carl, H., Hüssy, K., Greisen, K., Ebert, R., Møller, P.R., 2015. Invasion rate and population characteristics of the round goby Neogobius melanostomus: effects of density and invasion history. Aquat. Biol. 24, 41-52.

Bunnell, D.B., Johnson, T.B., Knight, C.T., 2005. The impact of introduced round gobies (Neogobius melanostomus) on phosphorus cycling in central Lake Erie. Can. J. Fish. Aquat. Sci. 62, 15-29.

Campana, S.E., 1990. How reliable are growth back-calculations based on otoliths? Can. J. Fish. Aquat. Sci. 47, 2219-2227.

Charlebois, P.M., Marsden, J. E., Goettel, R.G., Wolfe, R.K., Jude, D.J., Rudnicka, S., 1997. The round goby, Neogobius melanostomus (Pallas), a review of European and North American literature. Illinois-Indiana Sea Grant Program and Illinois Natural History Survey, Illinois Natural History Survey Special Publication 20, Champaign. 
Charlebois, P.M., Corkum, L.D., Jude, D.J., Knight, C., 2001. The round goby (Neogobiusmelanostomus) invasion: current research and future needs. J. Great Lakes Res. 27,263-266.

Chotkowski, M.A., Marsden, J.E., 1999. Round goby and mottled sculpin predation on lake trout eggs and fry: field predictions from laboratory experiments. J. Great Lakes Res. 25(1), 26-35.

Coulter, D.P., Murry, B.A., Webster, W.C., Uzarski, D.G., 2011. Effects of dreissenid mussels, chironomids, fishes, and zooplankton on growth of round goby in experimental aquaria. J. Freshw. Ecol. 26(2), 155-162.

Crane, N.A., Farrell,J.M., Einhouse,D.W., Lantry, J.R., Markham, J.L., 2015. Trends in body composition of native piscivores following invasion of Lake Erie and Ontario by the round goby. Freshw. Biol. 60,111-124.

Dietrich, J.P., Morrison, B.J., Hoyle, J.A., 2006. Alternative ecological pathways in the Eastern Lake Ontario food web-round goby in the diet of lake trout. J. Great. Lakes Res. 32(2), 395-400.

Fielder, D.G., Thomas, M.V., 2006.Fish Population Dynamics of Saginaw Bay, Lake Huron, 1998-2004. Michigan Department of Natural Resources, Fisheries Division.

Fielder, D.G., Schaeffer, J.S., Thomas, M.V., 2007.Environmental and ecological conditions surrounding the production of large year classes of walleye (Sander vitreus) in Saginaw Bay, Lake Huron. J. Great Lakes Res. 33, 118-132.

Francis, R.I.C.C., 1990. Back-calculation of fish length: a critical review. J. Fish Biol. 
36, 883-902.

French III, J.R.P., Jude, D.J., 2001. Diets and diet overlap of nonindigenous gobies and small benthic native fishes co-inhabiting the St. Clair River, Michigan. J. Great Lakes Res. 27(3), 300-311.

French III, J.R.P., Black, M.G., 2009. Maximum length and age of round gobies (Apolloniamelanostomus) in Lake Huron. J. Freshw. Ecol. 24, 173-175.

Grul'a, D., Balážová, M., Copp, G.H., Kováč, V., 2012. Age and growth of invasive round goby Neogobius melanostomus from middle Danube. Cent. Eur. J. Biol. 7, 448-459.

Gümüs, A., Kurt, A., 2009. Age structure and growth by otolith interpretation of Neogobius melanostomus (Gobiidae) from southern Black Sea. Cybium. 33(1), 29-37.

Gunn, J.S., Clear, N.P., Carter, T.I., Rees, A.J., Stanley, C.A., Farley, J.H., Kalish, J.M., 2008.Age and growth in southern bluefin tuna, Thunnus maccoyii (Castelnau): direct estimation from otoliths, scales and vertebrae. Fish. Res. 92, 207-220.

He, J.X., Bence, J.R., Madenjian, C.P., Pothoven, S.A., Dobiesz, N.E., Fielder,D.G., Johnson, J.E., Ebener, M.P., Cottrill, R.A., Mohr, L.C., Koproski, S.R., 2015. Coupling age-structured stock assessment and fishbioenergetics models: a system of time-varying models for quantifying piscivory patterns during the rapid trophic shift in the main basin of Lake Huron. Can. J. Fish. Aquat. Sci. 72(1), 7-23.

Huo, B., Madenjian, C. P., Xie, C. X., Zhao, Y., O’Brien, T. P., Czesny, S. J., 2014. 
Age and growth of round gobies in Lake Michigan, with preliminary mortality estimation. J. Great LakesRes. 40(3), 712-720.

Janssen, J., Jude, D.J., 2001. Recruitment failure of mottled sculpin Cottus bairdi in Calumet Harbor, southernLake Michigan, induced by the newly introduced round goby, Neogobius melanostomus. J. Great LakesRes. 27(3), 319-328.

Johnson, T.B., Bunnell, D.B., Knight, C.T., 2005. A potential new energy pathway in central Lake Erie: the round goby connection. J. Great Lakes Res. 31, 238-251. Jovanovic, C.M., 2013.Impacts of a recovering walleye population on an altered forage fish community in Saginaw Bay, Lake Huron. The University of Michigan (Maters Thesis). 53pp.

Jude, D.J., Reider, R.H., Smith, G.R., 1992. Establishment of Gobiidae in the Great Lakesbasin. Can. J. Fish. Aqua. Sci. 49, 416-421.

Jude, D. J., Janssen, J., Crawford, G. 1995. Ecology, distribution, and impact of the newly introduced round and tubenose gobies in the biota of the St. Clair and Detroit Rivers. In The Lake Huron Ecosystem: Ecology, Fisheries, and Management, eds. M. Munawar, T. Edsall, and J. Leach, pp. 447-460. Ecovision World Monograph Series, S. P.B. Academic Publishing, The Netherlands.

Jude, D.J., 1997. Round gobies: cyberfish of the third millennium. Great Lakes Res. Rev. 3, 27-34.

Kornis, M.S., Mercado-Silva, N., Vander Zanden, M.J., 2012. Twenty years of invasion: a review of round goby Neogobius melanostomus biology, spread and ecological implications. J. Fish Bio. 80(2), 235-285. 
Lynch, M.P.,Mensinger, A.F., 2013. Temporal patterns in growth and survival of the round goby Neogobius melanostomus. J. Fish Biol. 82, 111-124.

MacInnis, A.J., Corkum, L.D., 2000a. Age and growth of round gobyNeogobius melanostomus in the Upper Detroit River. Trans. Am. Fish. Soc. 129, 852-858.

MacInnis, A.J., Corkum, L.D., 2000b. Fecundity and reproductive season of the round goby Neogobius melanostomus in the upper Detroit River. Trans. Am. Fish. Soc. 129, 136-144.

Madenjian, C.P., Stapanian, M.A., Witzel, L.D., Einhouse, D.W., Pothoven, S.A., Whitford, H.L., 2011. Evidence for predatory control of the invasive round goby. Biol. Invasions 13(4), 987-1002.

Nikolski, G., 1956. Detailed Ichthyology. Państwowe Wydawnictwo Rolniczei Lesne, Warsaw.

Phelps, Q.E., Edwards, K.R., Willis, D.W., 2007. Precision of five structures for estimating age of common carp. N. Am. J. Fish Manage. 27,103-105.

Phillips, E.C., Washek, M.E., Hertel, A.W., Niebel, B.M., 2003. The round goby (Neogobiusmelanostomus) in Pennsylvania tributary streams of Lake Erie. J. Great Lakes Res. 29(1), 34-40.

Pothoven, S.A., Madenjian, C.P., 2013. Increased piscivory by lake whitefish in Lake Huron. N. Am. J. Fish. Manage. 33(6), 1194-1202.

Quinn, T.J. II., Deriso, R.B., 1999. Quantitative Fish Dynamics. Oxford University Press, NewYork.

Ricker, W.E., 1975. Computation and interpretation of biological statistics of fish 
populations.Bull Fish. Res. Board Can. 191.

Rodriguez, L.F., 2006. Can invasive species facilitate native species? Evidence of how, when, and why these impacts occur. Biol. Invasions. 8, 927-939.

Ruiz, G.M., Carlton, J.T., Grosholz, E.D., Hines, A.H., 1997. Global invasions of marine and estuarine habitats by nonindigenous species: mechanisms, extent, and consequences. Am. Zool. 37(6), 621-632.

Seber, G.A.F., 1982. The Estimation of Animal Abundance, Second ed. Griffin, London.

Simberloff, D., 2003. How much information on population biology is needed to manage introduced species? Conserv. Biol. 17, 83-92

Smith, M.W., Then, A.Y., Wor, C., Ralph, G., Pollock, K.H., Hoenig, J.M., 2012. Recommendations for catch-curve analysis. N. Am. J. Fish. Manage. 2012, 32(5), 956-967.

Sokołowska, E., Fey, D.P., 2011. Age and growth of the round goby Neogobius melanostomus in the Gulf of Gdańsk several years after invasion. Is the Baltic Sea a new Promised Land? J. Fish.Biol. 78(7), 1993-2009.

Sponaugle, S., 2009. Daily otolith increments in the early stages of tropical fish. In: Green BS, Mapstone BD, Carlos G, Begg GA (eds) Tropical fish otoliths: information for assessment, management and ecology. Springer, Dordrecht, pp. 93-132.

Steinhart, G.B., Stein, R.A., Marschall, E.A., 2004. High growth rate of young-of-the-year smallmouth bass in Lake Erie: a result of the round 
gobyinvasion? J. Great Lakes Res. 30, 381-389.

Taraborelli, A.C., Fox, M.G., Johnson, T.B., Schaner, T., 2010. Round goby

(Neogobius melanostomus) population structure, biomass, prey consumption and mortality from predation in the Bay of Quinte, Lake Ontario. J.Great Lakes Res. 36(4), 625-632.

Truemper, H.A., Lauer, T.E., 2005. Gape limitation and piscine prey size-selection by yellow perch in the extreme southern location of Lake Michigan, with emphasis on two exotic prey items. J. Fish Biol. 66(1), 135-149.

Van Den Avyle, M.J., Hayward, R.S., 1999. Dynamics of exploited fish populations, In: Kohler, C.C., Hubert, W.A. (Eds.), Inland Fisheries Management in North America, 2nd editionAmerican Fisheries Society, Bethesda, Maryland, pp. 119-127.

Veitch, C.R., Clout, M.N., 2002. Turning the tide: the eradication of invasive species: Proceedings of the International Conference on Eradication of Island Invasives, No. 27, IUCN.

Vélez-Espino, L.A., Koops, M.A., Balshine, S., 2010. Invasion dynamics of round goby (Neogobius melanostomus) in Hamilton Harbour, Lake Ontario. Biol. Invasions 12, 3861-3875.

Zavaleta, E.S., Hobbs, R.J., Mooney, H.A., 2001. Viewing invasive species removal in a whole-ecosystem context. Trends. Ecol. Evol. 16(8), 454-459. 


\section{Table 1}

Analysis of covariance forthe body-otolith relationships for round goby (Neogobius melanostomus) among four locations in Lake Huron for each sex during 2014. LOC is location, OR denotes otolith radius and LOC : OR is the interaction term. *: significant level at $\alpha=0.05$; **: significant level at $\alpha=0.01 ; * *$ : significant level at $\alpha=0.001$.

\begin{tabular}{|c|c|c|c|c|c|c|c|c|}
\hline \multirow{2}{*}{ Model Term } & \multicolumn{4}{|c|}{ Female } & \multicolumn{4}{|c|}{ Male } \\
\hline & LOC & OR & LOC:OR & Residuals & LOC & OR & LOC:OR & Residuals \\
\hline Degree of freedom & 3 & 1 & 3 & 303 & 3 & 1 & 3 & 431 \\
\hline Mean squares & 0.009 & 0.725 & $<0.001$ & 0.001 & 0.01 & 2.074 & 0.002 & 0.002 \\
\hline$F$-value & 6.473 & 512.232 & 0.239 & & 4.118 & 861.818 & 0.886 & \\
\hline$P$-value & $<0.001^{* * *}$ & $<0.001^{* * *}$ & 0.869 & & $0.007^{* *}$ & $<0.001^{* * *}$ & 0.459 & \\
\hline
\end{tabular}




\section{Table 2}

Analysis of covariance for the body-otolith relationships for round goby (Neogobius melanostomus) between sexes for each location in Lake Huron during 2014. OR denotes otolith radius and SEX : OR is the interaction term. *: significant level at $\alpha=0.05$; **: significant level at $\alpha=$ $0.01 ; * * *$ : significant level at $\alpha=0.001$.

\begin{tabular}{|c|c|c|c|c|c|c|c|c|c|c|c|c|c|c|c|c|}
\hline \multirow{2}{*}{ Model Term } & \multicolumn{4}{|c|}{ Saginaw Bay } & \multicolumn{4}{|c|}{ Rockport } & \multicolumn{4}{|c|}{ Hammond Bay } & \multicolumn{4}{|c|}{ Thunder Bay } \\
\hline & Sex & OR & Sex:OR & Residuals & Sex & OR & $\begin{array}{l}\text { Sex:OR } \\
\end{array}$ & Residuals & Sex & OR & Sex:OR & Residuals & Sex & OR & Sex:OR & Residuals \\
\hline Degree of freedom & 1 & 1 & 1 & 197 & 1 & 1 & 1 & 148 & 1 & 1 & 1 & 196 & 1 & 1 & 1 & 193 \\
\hline Sum of squares & 0.018. & 0.474 & 0.013 & 0.301 & 0.026 & 0.761 & 0.367 & 0.367 & 0.040 & 0.525 & 0.005 & 0.389 & 0.023 & 0.687 & 0.004 & 0.409 \\
\hline Mean squares & 0.018 & 0.474 & 0.013 & 0.002 & 0.026 & 0.761 & 0.020 & 0.002 & 0.040 & 0.525 & 0.005 & 0.002 & 0.023 & 0.687 & 0.004 & 0.002 \\
\hline$F$-value & 11.397 & 310.050 & 8.669 & & 10.483 & 306.360 & 0.880 & & 19.998 & 264.023 & 2.278 & & 10.929 & 324.685 & 1.816 & \\
\hline$P$-value & $0.001^{* * *}$ & $<0.001^{* * *}$ & $0.004 * *$ & & $0.001 * * *$ & $<0.001 * * *$ & 0.350 & & $<0.001^{* * *}$ & $<0.001 * * *$ & 0.133 & & $0.001^{* * *}$ & $<0.001 * * *$ & 0.179 & \\
\hline
\end{tabular}




\section{Table 3}

Growth variation tests of round goby (Neogobius melanostomus)among four locations for each sex in Lake Huron during 2014.*: significant level at $\alpha=0.0083$; **: significant level at $\alpha=0.0017 ; * * *$ : significant level at $\alpha=0.00017 ; L_{\mathrm{F}}$ : maximum likelihood for full model; $L_{\mathrm{R}}$ : maximum likelihoodfor reduced model; SB: Saginaw Bay; RP: Rockport; HB: Hammond Bay; TB: Thunder Bay.

\begin{tabular}{|c|c|c|c|c|c|c|}
\hline Model Term & SB-RP & SB-HB & SB-TB & RP-HB & RP-TB & HB-TB \\
\hline & \multicolumn{6}{|c|}{ Male } \\
\hline $\operatorname{Ln}\left(L_{\mathrm{F}}\right)$ & 248.3127 & 269.4531 & 218.3871 & 308.0587 & 255.4007 & 277.0790 \\
\hline $\operatorname{Ln}\left(L_{\mathrm{R}}\right)$ & 247.8882 & 260.9980 & 202.4745 & 297.4738 & 243.1866 & 261.1774 \\
\hline$\chi^{2}$ & 0.8489 & 16.9102 & 31.8553 & 21.1698 & 24.4283 & 31.8032 \\
\hline Degree of freedom & 3 & 3 & 3 & 3 & 3 & 3 \\
\hline \multirow[t]{2}{*}{$P$-value } & 0.8377 & $0.0007^{* *}$ & $<0.0001^{* * *}$ & $<0.0001^{* * *}$ & $<0.0001^{* * *}$ & $<0.0001^{* * *}$ \\
\hline & \multicolumn{6}{|c|}{ Female } \\
\hline $\operatorname{Ln}\left(L_{\mathrm{F}}\right)$ & 187.3203 & 270.2618 & 291.6182 & 188.6645 & 207.8377 & 295.0115 \\
\hline $\operatorname{Ln}\left(L_{\mathrm{R}}\right)$ & 181.4395 & 261.7718 & 272.2761 & 185.2627 & 185.6493 & 246.4532 \\
\hline$\chi^{2}$ & 11.7616 & 16.9800 & 38.6843 & 6.8037 & 44.3767 & 97.1165 \\
\hline Degree of freedom & 3 & 3 & 3 & 3 & 3 & 3 \\
\hline$P$-value & $0.0082 *$ & $0.0007^{* *}$ & $<0.0001^{* * *}$ & 0.0784 & $<0.0001^{* * *}$ & $<0.0001^{* * *}$ \\
\hline
\end{tabular}




\section{Table 4}

Growth variation tests of round goby (Neogobius melanostomus)betweensexes for eachlocation in Lake Huron during 2014. *: significant level at $\alpha=0.05 ; * *$ : significant level at $\alpha=0.01$; ***: significant level at $\alpha=0.001 ; L_{\mathrm{F}}$ : maximumlikelihood for full model; $L_{\mathrm{R}}$ : maximumlikelihood for reduced model

\begin{tabular}{|c|c|c|c|c|}
\hline \multirow{2}{*}{ Statistic } & Saginaw Bay & Rockport & Hammond Bay & Thunder Bay \\
\hline & Male-Female & Male-Female & Male-Female & Male-Female \\
\hline $\operatorname{Ln}\left(L_{\mathrm{F}}\right)$ & 239.8442 & 194.0844 & 297.9598 & 265.3361 \\
\hline $\operatorname{Ln}\left(L_{\mathrm{R}}\right)$ & 218.1185 & 182.9260 & 277.3678 & 253.2455 \\
\hline$\chi^{2}$ & 43.4513 & 22.3168 & 41.1839 & 24.1813 \\
\hline Degree of freedom & 3 & 3 & 3 & 3 \\
\hline$P$-value & $<0.001 * * *$ & $<0.001^{* * *}$ & $<0.001 * * *$ & $<0.001 * * *$ \\
\hline
\end{tabular}




\section{Table5}

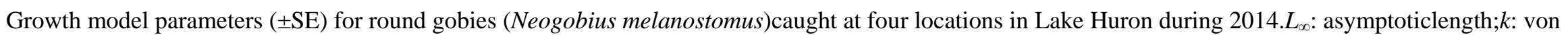
Bertalanffy growth constant; $t_{0}$ : theoretical age at zero length; $\mathrm{N}$ : number of back-calculated total lengths at age.

\begin{tabular}{|c|c|c|c|c|c|c|c|c|}
\hline \multirow{2}{*}{ Parameter } & \multicolumn{2}{|c|}{ Saginaw Bay } & \multicolumn{2}{|c|}{ Rockport } & \multicolumn{2}{|c|}{ Hammond Bay } & \multicolumn{2}{|c|}{ Thunder Bay } \\
\hline & Male & Female & Male & Female & Male & Female & Male & Female \\
\hline$L_{\infty}(\mathrm{mm})$ & $147.41 \pm 47.45$ & $75.32 \pm 7.43$ & $155.20 \pm 30.56$ & $152.12 \pm 68.93$ & $138.73 \pm 22.40$ & $91.61 \pm 9.343$ & $126.49 \pm 15.54$ & $108.23 \pm 11.79$ \\
\hline$k\left(\right.$ year $\left.^{-1}\right)$ & $0.203 \pm 0.098$ & $0.589 \pm 0.167$ & $0.185 \pm 0.057$ & $0.144 \pm 0.099$ & $0.181 \pm 0.052$ & $0.315 \pm 0.072$ & $0.255 \pm 0.061$ & $0.267 \pm 0.068$ \\
\hline$t_{0}$ & $-0.160 \pm 0.152$ & $-0.008 \pm 0.168$ & $-0.240 \pm 0.129$ & $-0.735 \pm 0.343$ & $-0.625 \pm 0.202$ & $-0.482 \pm 0.169$ & $-0.315 \pm 0.151$ & $-0.730 \pm 0.252$ \\
\hline$R^{2}$ & 0.817 & 0.764 & 0.854 & 0.841 & 0.808 & 0.870 & 0.831 & 0.750 \\
\hline $\mathrm{N}$ & 202 & 200 & 230 & 73 & 251 & 147 & 192 & 199 \\
\hline
\end{tabular}




\section{Table6}

Maximum total length and totallengthatage of round goby (Neogobius melanostomus)from different locations. Data for males and females are separated $(/)$. Lengths reported in the literature as standard length were converted to total length using the following equation: $T L=1.1977 \times S L+$ $0.4586\left(R^{2}=0.9932, \mathrm{n}=193\right)$ (Kornis et al., 2012). n/a denotes no data were available. *: observed total length; ${ }^{\dagger}:$ denotes that standard length reported from source and converted to total length using equation in table heading; —: no data; MTL: maximum total length; TL: total length; SL: standard length.

\begin{tabular}{|c|c|c|c|c|c|c|c|c|c|c|c|}
\hline & & \multicolumn{8}{|c|}{ Age (years) } & \multirow[b]{3}{*}{ Max } & \multirow[b]{3}{*}{ Source } \\
\hline & & 0 & 1 & 2 & 3 & 4 & 5 & 6 & 7 & & \\
\hline Region & $M T L(\mathrm{~mm})$ & \multicolumn{8}{|c|}{$T L(\mathrm{~mm})$} & & \\
\hline Harbor Beach, Lake Huron ${ }^{*}$ & $97 /-$ & $\mathrm{n} / \mathrm{a}$ & $40 /-$ & $61 /-$ & $77 /-$ & $89 /-$ & $97 /-$ & $\mathrm{n} / \mathrm{a}$ & $\mathrm{n} / \mathrm{a}$ & $5 /-$ & French and Black (2009) \\
\hline Hammond Bay, Lake Huron* & $105 /-$ & $\mathrm{n} / \mathrm{a}$ & $45 /-$ & $72 /-$ & $87 /-$ & $98 /-$ & $105 /-$ & $\mathrm{n} / \mathrm{a}$ & $\mathrm{n} / \mathrm{a}$ & $5 /-$ & French and Black (2009) \\
\hline Hammond Bay, Lake Huron ${ }^{*}$ & $119 / 75$ & $\mathrm{n} / \mathrm{a}$ & $\mathrm{n} / \mathrm{a}$ & $65 / 55$ & $67 / 59$ & $77 / 67$ & $87 / 75$ & $100 /-$ & $119 /-$ & $7 / 5$ & Present Study \\
\hline Rockport, Lake Huron ${ }^{*}$ & $104 / 115$ & $\mathrm{n} / \mathrm{a}$ & $\mathrm{n} / \mathrm{a}$ & $57 / 52$ & $65 / 59$ & $81 / 72$ & $93 / 78$ & $104 / 115$ & $\mathrm{n} / \mathrm{a}$ & $6 / 6$ & Present Study \\
\hline Saginaw Bay, Lake Huron* & $101 / 74$ & $\mathrm{n} / \mathrm{a}$ & $\mathrm{n} / \mathrm{a}$ & $56 / 62$ & $67 / 62$ & $83 / 74$ & $101 /-$ & $\mathrm{n} / \mathrm{a}$ & $\mathrm{n} / \mathrm{a}$ & $5 / 4$ & Present Study \\
\hline Thunder Bay, Lake Huron* & $112 / 100$ & $\mathrm{n} / \mathrm{a}$ & $\mathrm{n} / \mathrm{a}$ & $63 / 60$ & $71 / 68$ & $83 / 79$ & $100 / 80$ & $112 / 98$ & $109 / 100$ & $7 / 7$ & Present Study \\
\hline Sleeping Bear Dunes, Lake Michigan* & $129 / 112$ & $\mathrm{n} / \mathrm{a}$ & $\mathrm{n} / \mathrm{a}$ & $71 / 79$ & $90 / 80$ & $102 / 94$ & 119/105 & $-/ 111$ & $\mathrm{n} / \mathrm{a}$ & $5 / 6$ & Huo et al. (2014) \\
\hline Sturgeon Bay, Lake Michigan* & $131 / 119$ & $\mathrm{n} / \mathrm{a}$ & $\mathrm{n} / \mathrm{a}$ & $55 / 73$ & $75 / 74$ & $89 / 90$ & 103/96 & $\mathrm{n} / \mathrm{a}$ & $131 /-$ & $7 / 5$ & Huo et al. (2014) \\
\hline Waukegan, Lake Michigan* & $125 / 107$ & $\mathrm{n} / \mathrm{a}$ & $\mathrm{n} / \mathrm{a}$ & $70 / 68$ & $83 / 83$ & 96/95 & $113 /-$ & $\mathrm{n} / \mathrm{a}$ & $\mathrm{n} / \mathrm{a}$ & $5 / 4$ & Huo et al. (2014) \\
\hline Upper Detroit River* & $124 / 112$ & $\mathrm{n} / \mathrm{a}$ & $76 / 70$ & $91 / 78$ & $-/ 100$ & $\mathrm{n} / \mathrm{a}$ & $\mathrm{n} / \mathrm{a}$ & $\mathrm{n} / \mathrm{a}$ & $\mathrm{n} / \mathrm{a}$ & $2 / 3$ & MacInnis and Corkum (2000a) \\
\hline $\begin{array}{l}\text { Pennsylvania Tributary } \\
\text { Streams, Lake Erie* }\end{array}$ & $112 /-$ & $44 /-$ & $68 /-$ & $80 /-$ & $94 /-$ & $\mathrm{n} / \mathrm{a}$ & $\mathrm{n} / \mathrm{a}$ & $\mathrm{n} / \mathrm{a}$ & $\mathrm{n} / \mathrm{a}$ & $4 /-$ & Phillips et al. (2003) \\
\hline Central Basin Lake Erie ${ }^{*}$ & $190 / 144$ & $55 / 49$ & $75 / 70$ & $104 / 90$ & $148 / 130$ & $177 /-$ & $\mathrm{n} / \mathrm{a}$ & $\mathrm{n} / \mathrm{a}$ & $\mathrm{n} / \mathrm{a}$ & $4 / 3$ & Johnson et al. (2005) \\
\hline Southern Black Sea ${ }^{\dagger}$ & $250 / 197$ & $\mathrm{n} / \mathrm{a}$ & $107 / 103$ & $140 / 129$ & $162 / 147$ & $183 / 168$ & 190/182 & $\mathrm{n} / \mathrm{a}$ & $\mathrm{n} / \mathrm{a}$ & 5 & Gümüs and Kurt (2009) \\
\hline Gulf of Gdańsk $^{*}$ & $235 / 187$ & $\mathrm{n} / \mathrm{a}$ & $\mathrm{n} / \mathrm{a}$ & $119 / 94$ & $136 / 125$ & $146 / 133$ & $155 / 144$ & 209/175 & $\mathrm{n} / \mathrm{a}$ & 6 & Sokołowska and Fey (2011) \\
\hline Caspian Sea* & $190 / 160$ & $\mathrm{n} / \mathrm{a}$ & $69 / 63$ & $88 / 67$ & $111 / 81$ & $138 / 85$ & $\mathrm{n} / \mathrm{a}$ & $\mathrm{n} / \mathrm{a}$ & $\mathrm{n} / \mathrm{a}$ & 4 & Nikolski (1956) \\
\hline
\end{tabular}




\section{Figure captions}

Fig. 1.Map of sampling locations at Saginaw Bay, Rockport, Hammond Bay, and Thunder Bay in Lake Huron for round gobies (Neogobius melanostomus)during 2014.

Fig. 2. Total length composition by sex of round gobies(Neogobius melanostomus)from four locations inLake Huron during 2014.

Fig. 3. Age composition by sexof round gobies(Neogobius melanostomus)caught at four locations inLake Huron during 2014.

Fig. 4.Body-otolith relationships,by location and sex, of round gobies(Neogobius melanostomus)in Lake Huron during 2014. Lines represent fitted regression lines. Symbols representobserved values.

Fig. 5. Fitted von Bertalanffy growth curves, by sex, for round gobies fromfourlocations inLake Huron. Symbols representback-calculatedtotal lengths.

Fig. 6. Catch curve for round gobies (Neogobius melanostomus) from Hammond Bay in Lake Huron during 2014. The fitof natural logarithm of number of fish as a function of age, for ages 4-6, by simple linear regressionanalysis yielded an estimate of the instantaneousmortality rate $Z$. 


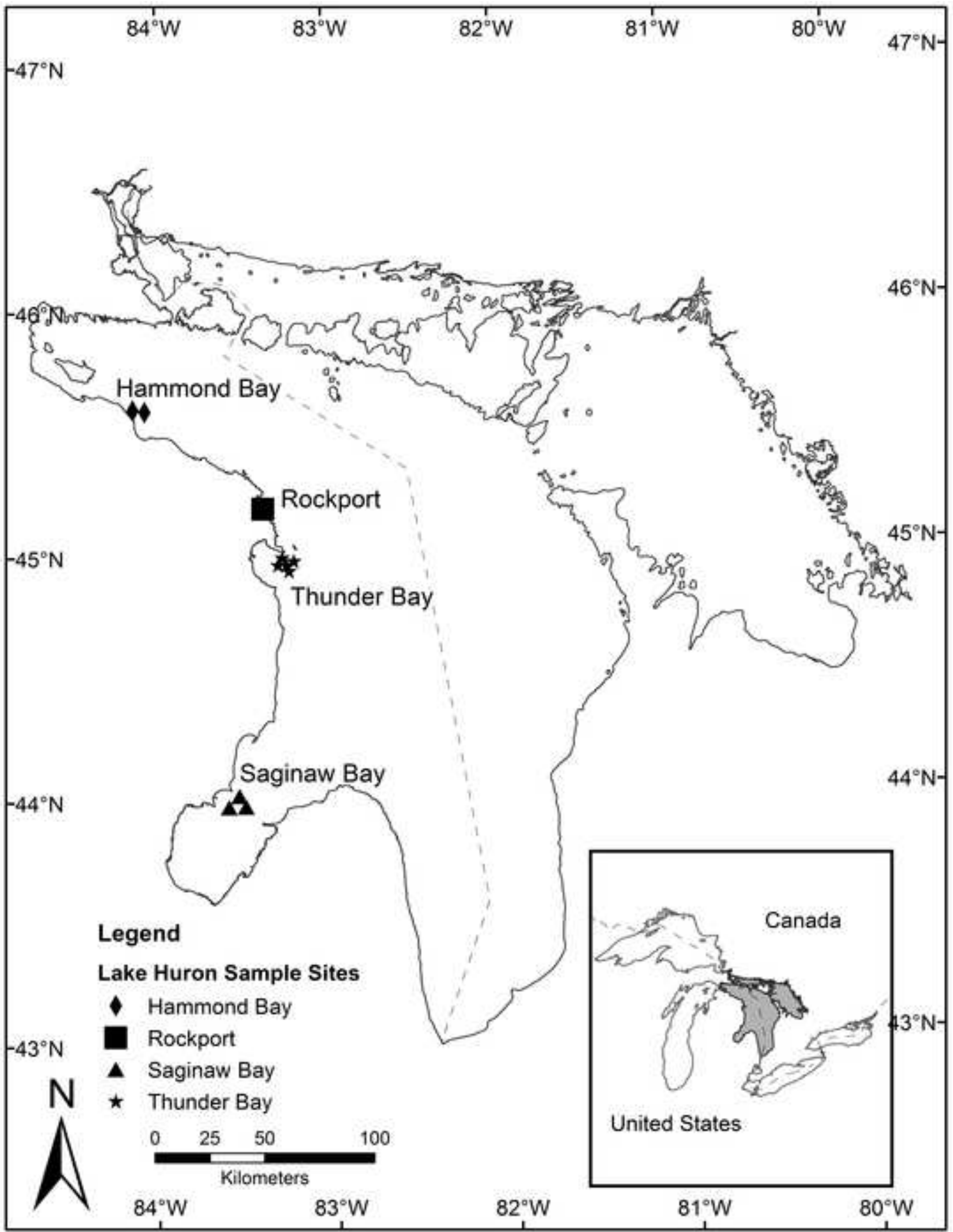




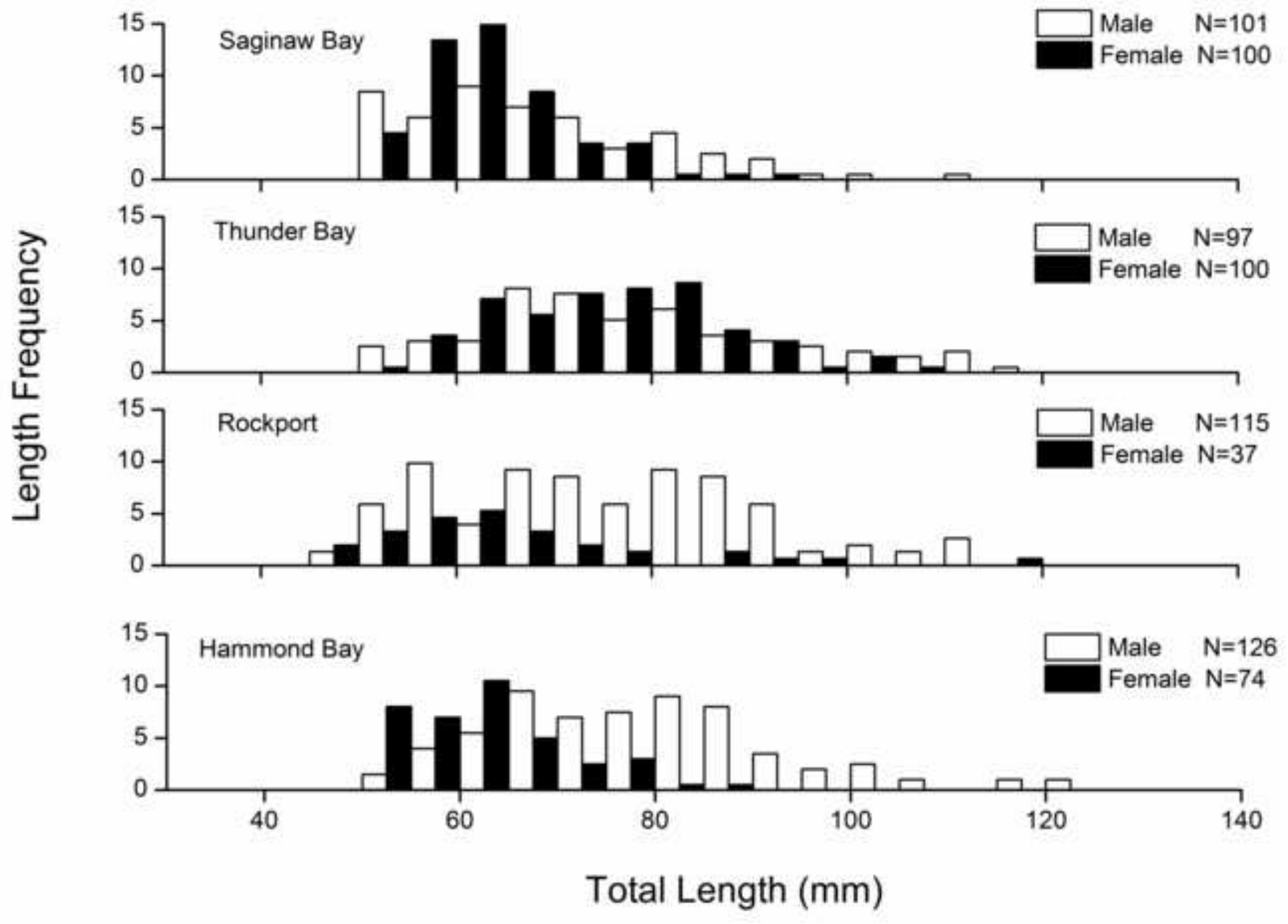




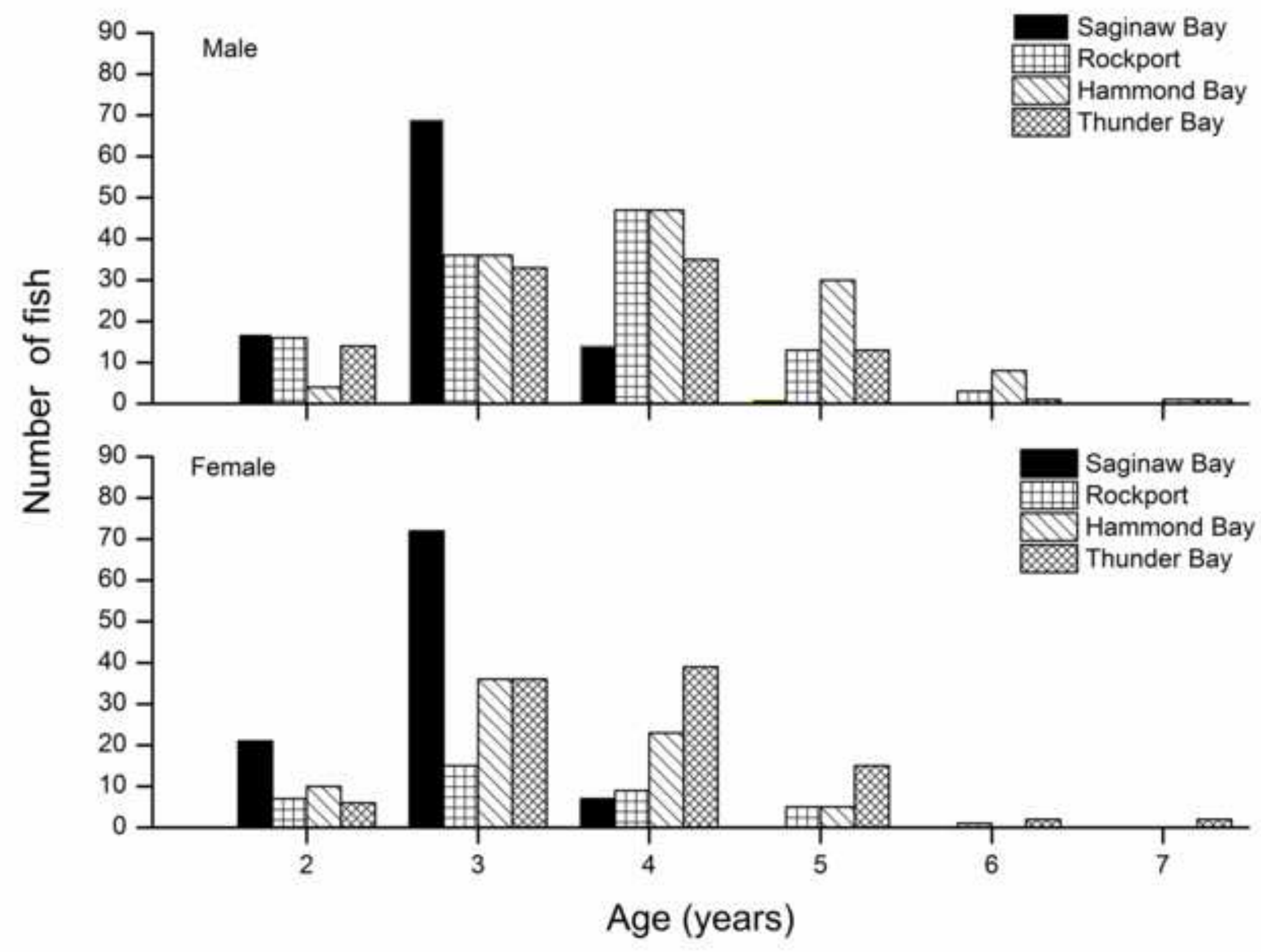




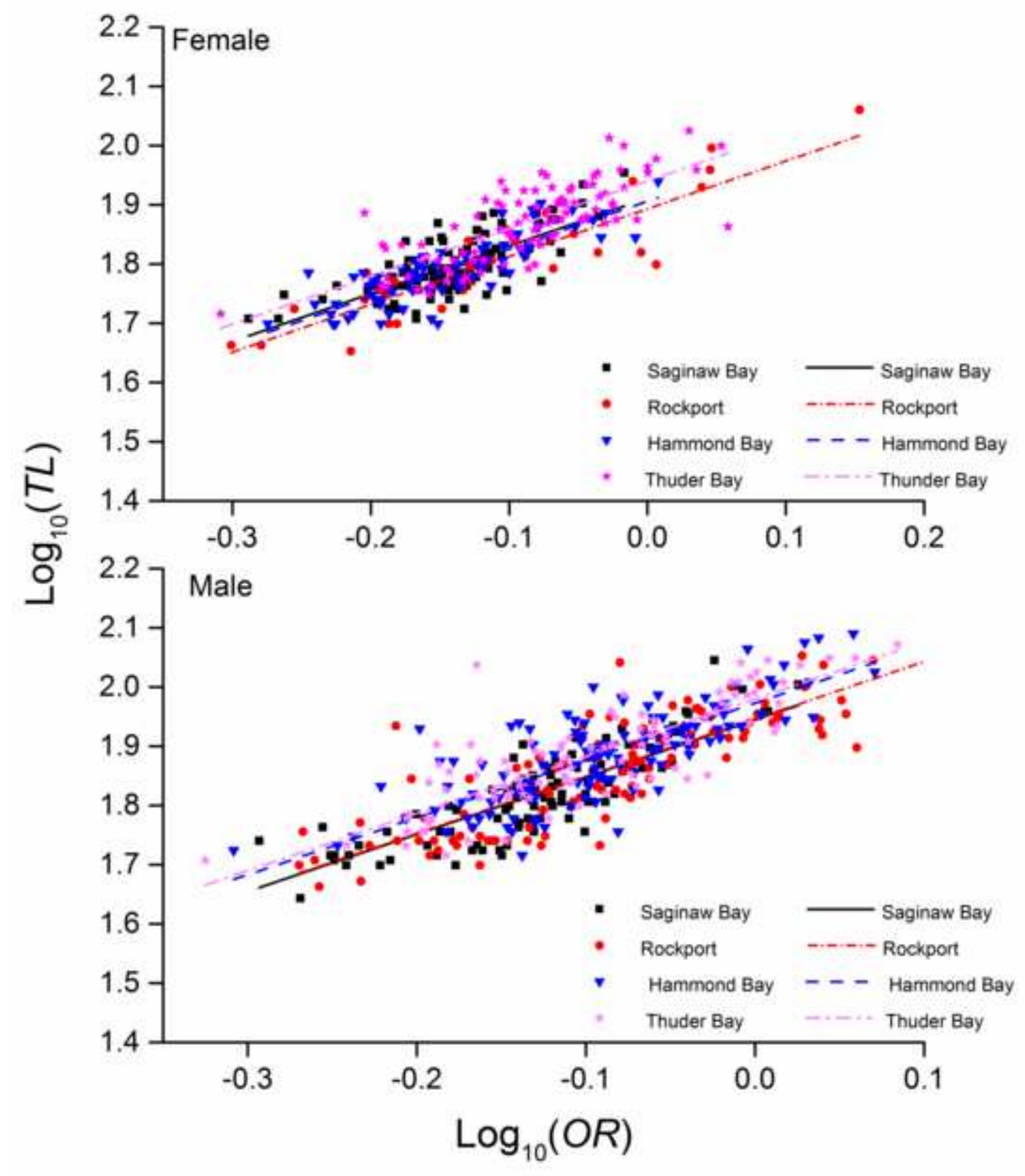

Figure 4 


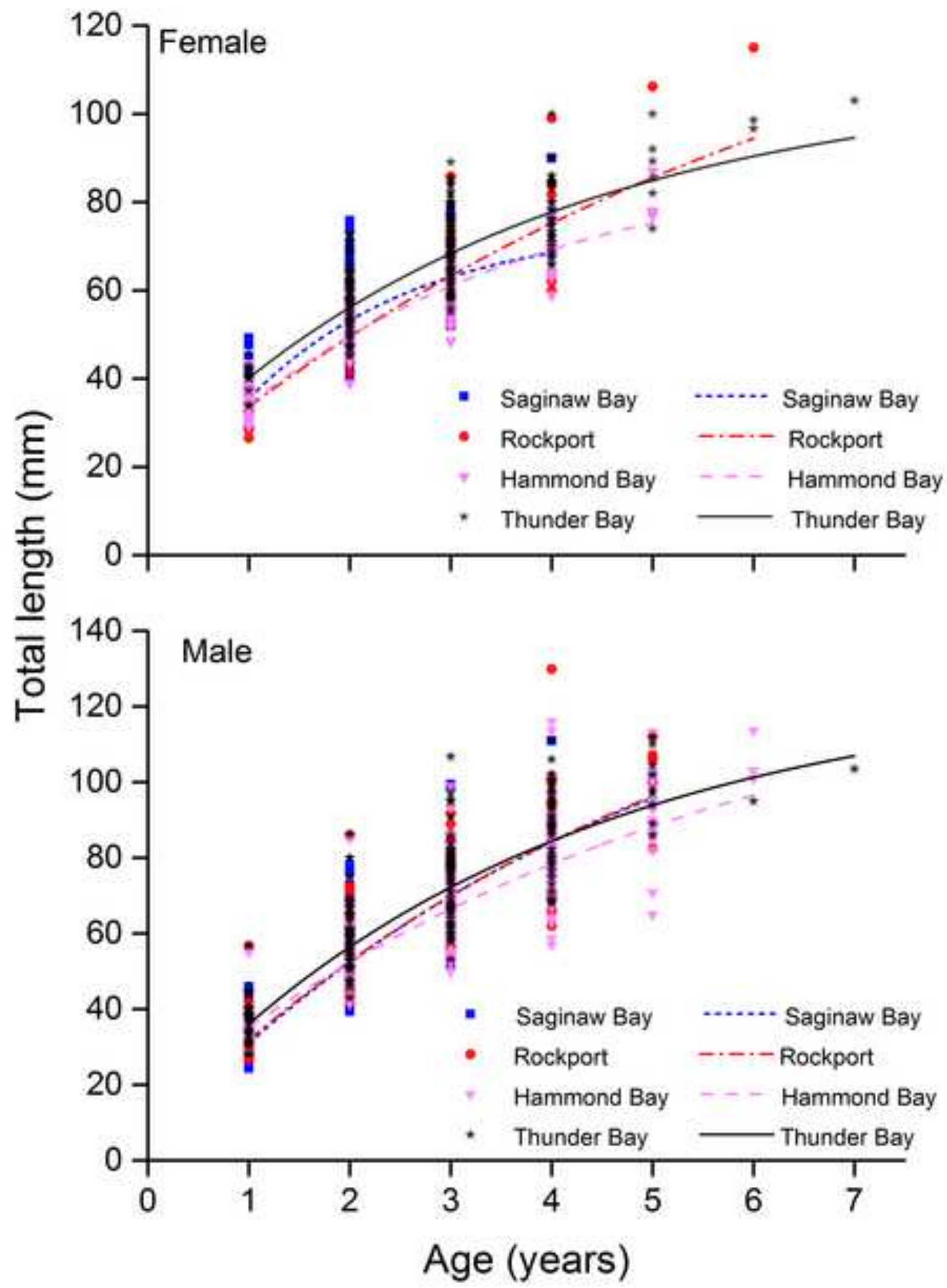




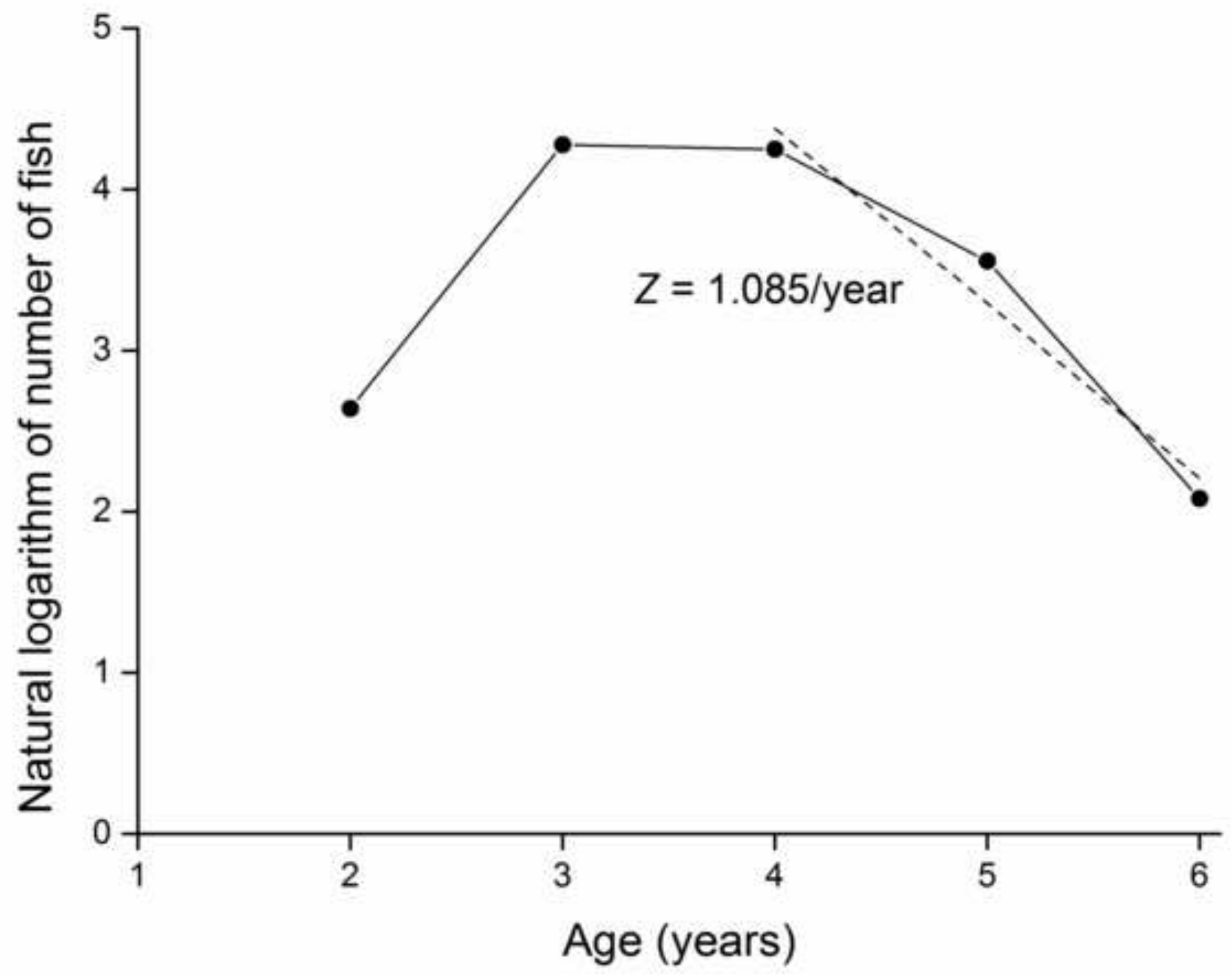

